\title{
Anti-oxidant and anti-inflammatory effects of rice bran and green tea fermentation mixture on lipopolysaccharide- induced RAW 264.7 macrophages
}

\author{
Yun-Hee Rhee ${ }^{1}$, Chun Hee Rhee ${ }^{2}$, Phil-Sang Chung ${ }^{1,3}$, Jin-Chul Ahn ${ }^{1}$ \\ ${ }^{1}$ Beckman Laser Institute Korea, Dankook University, Cheonan 31116, ${ }^{2}$ Enzyme LAPA. Co., Buldang 955, Cheonan 31114, \\ ${ }^{3}$ Laser Translational Clinical Trial Center, Dankook University, Cheonan 31116, Republic of Korea \\ *For correspondence: Email: jcahn@dankook.ac.kr; Tel: +82-41-550-3889; Fax: +82-41-559-7838
}

\begin{abstract}
Purpose: To investigate the anti-inflammatory and anti-oxidant properties of an enzyme bath of Oryza sativa (rice bran) and Camellia sinensis $O$. Kuntz (green tea) fermented with Bacillus subtilis (OCB). Methods: The anti-oxidant effects of OCB were assessed by 2,2-Diphenyl-1-picrylhydrazyl (DPPH) assay and flow cytometry. The anti-inflammatory effects of OCB were assessed by a nitric oxide (NO) assay. Enzyme-linked immunosorbent assay and real-time polymerase chain reaction were used to quantify expression of pro-inflammatory cytokines in lipopolysaccharide (LPS)-stimulated RAW 264.7 macrophages. The major compounds of OCB were identified using high performance liquid chromatography (HPLC) analysis.

Results: OCB had no cytotoxic effect on LPS-stimulated macrophages or peripheral blood mononuclear cells up to $1 \mathrm{mg} / \mathrm{mL}$. OCB displayed anti-oxidant effects comparable to those of ascorbic acid and reduced reactive oxygen species (ROS) levels in target cells. OCB treatment of LPSstimulated mavrophages decreased nitric oxide (NO), NO synthase (iNOS), cyclooxygenase-2 (COX-2), prostaglandin E2 (PGE2) and key pro-inflammatory cytokine expressions, suggesting that OCB acts as an anti-oxidant and anti-inflammatory agent by reducing ROS levels and inhibiting pro-inflammatory mediators. The main effector compounds in OCB were epicatechin gallate, cathechin, synigrin acid, epicathechin, epigallocatechin gallate, rutin, and isoquercetin, which are known anti-oxidants.

Conclusion: OCB fermentation product may be used as synergistic adjuvant therapy for inflammatory diseases.
\end{abstract}

Keywords: Rice bran, Green tea, Bacillus subtilis, Enzyme bath, Anti-oxidant, Anti-inflammation

\begin{abstract}
This is an Open Access article that uses a funding model which does not charge readers or their institutions for access and distributed under the terms of the Creative Commons Attribution License (http://creativecommons.org/licenses/by/4.0) and the Budapest Open Access Initiative (http://www.budapestopenaccessinitiative.org/read), which permit unrestricted use, distribution, and reproduction in any medium, provided the original work is properly credited.

Tropical Journal of Pharmaceutical Research is indexed by Science Citation Index (SciSearch), Scopus, International Pharmaceutical Abstract, Chemical Abstracts, Embase, Index Copernicus, EBSCO, African Index Medicus, JournalSeek, Journal Citation Reports/Science Edition, Directory of Open Access Journals (DOAJ), African Journal Online, Bioline International, Open-J-Gate and Pharmacy Abstracts
\end{abstract}

\section{INTRODUCTION}

Enzyme baths have traditionally been used in Asian countries to treat various neurological disorders. More recently, enzyme baths were officially used at the $11^{\text {th }}$ Winter Olympics Games of 1972 in Sapporo, Japan to reduce athlete fatigue. Enzyme bath is made in tubs through the fermentation of sawdust or rice bran using microbial enzymes. This fermentation process generates heat that, when combined with useful fermentation metabolites, improves the 
physiology of the human body by augmenting blood circulation and immune function. Although well known for its beneficial properties on body condition, the physiological properties of enzyme bath have only been poorly studied. One way that enzyme baths may stimulate repair is through modulation of the immune system. Inflammation is a normal physiological response to counteract the assault of chemicals, microbial pathogens. Macrophages are major immune cells that mediate this inflammatory response by responding to cytokines and secreting proinflammatory mediators including nitric oxide $(\mathrm{NO})$, prostaglandin $\mathrm{E}_{2}\left(\mathrm{PGE}_{2}\right)$, tumor necrosis factor (TNF)- $\alpha$, interleukin (IL)-1 $\beta$, and IL-6. However, an unbalanced or prolonged inflammatory state can lead to progressive tissue damage. Indeed, prolonged inflammatory conditions are implicated in the development of chronic diseases such as cancer and neurodegenerative disorders. Given the relationship between inflammation and tissue repair, the effects of an enzyme bath on inflammation and macrophage activation warrants investigation.

In this study, we examined the effect of metabolites of rice bran, green tea, and microbial enzymes from fermentation on oxidative stress and pro-inflammatory cytokine production in cultured cells. Various components of the enzyme bath are well known for their biological properties. Rice bran is a source of antioxidants, vitamins, fatty acids, protein, carbohydrates, and other critical minerals [1-3], Polyphenols of green tea are recognized for their anti-cancer or antiinflammation properties [4-7]. We examined the cytotoxicity of OCB extract on both primary peropheral blood mononuclear cells (PBMCs) and RAW 264.7 macrophages. We purchased the product of fermented Oryza sativa (rice bran) and Camellia sinensis $O$. Kuntz (green tea) fermented from Bacillus subtilis (Enzyme LAPA $\mathrm{Co}$,) and extracted with ethanol (OCB; Figure 1). We characterized the anti-oxidant potency of OCB using 2,2-diphenyl-1-picrylhydrazyl (DPPH) assay and examined its protective effect against oxidative damage from reactive oxygen species (ROS) in lipopolysaccharide (LPS)-induced RAW 264.7 macrophages. We also measured the expression of inducible NO synthase (iNOS), TNF- $\alpha$, IL-6, and cyclooxygenase-2 (COX-2) by real-time polymerase chain reaction (PCR), the expression of NO by NO detection assay, and the expression of $\mathrm{PGE}_{2}$ by enzyme-linked immunosorbent assay (ELISA). Finally, we identified key components in the fermentation products of OCB using high-performance liquid chromatography (HPLC). Together these data elucidate a mechanism for the therapeutic properties of enzyme bath and suggest that it might be used for the treatment of inflammatory disorders.

\section{EXPERIMENTAL}

\section{Chemicals and reagents}

Dulbecco's modified Eagle's medium (DMEM), fetal bovine serum (FBS), and penicillinstreptomycin were purchased from WelGENE Co. (Daejeon, Korea). The enzyme immunoassay kit for $P G E_{2}$ was obtained from Cayman (Ann Arbor, MI, USA). The glutathione (GSH)/glutathione disulfide (GSSG) ratio detection assay kit was purchased from Abcam (Cambridge, MA, USA). LPS and 2',7'dichlorofluorescin diacetate (DCFH-DA) were purchased from eBioscience (Campbell, CA, USA). The Griess reagent system was purchased from Promega (Madison, WI, USA). 3(4,5-dimethylthiazol-2-yl)-2,5-diphenyltetrazolium bromide (MTT), DPPH, and other chemicals were purchased from Sigma-Aldrich (St. Louis, MO, USA).

\section{Preparation of ethanol extract from OCB}

A mixture of $1220 \mathrm{~g} \mathrm{O}$. sativa and $450 \mathrm{~g} \mathrm{C}$. sinensis $\mathrm{O}$. Kuntz was fermented with $600 \mathrm{~mL} B$. subtilis culture fluid at $30{ }^{\circ} \mathrm{C}$ in a fermentator for 7 days. After fermentation, filtered supernatant from OCB fluid was removed and concentrated using a rotary evaporator (Eyela, Tokyo, Japan). The powder from OCB fluid was extracted with $70 \%$ ethanol for 3 days at room temperature. The crude ethanol extract for OCB was evaporated, and the yield was measured to be $38.6 \%$. The lyophilized powder was dissolved in $10 \%$ dimethyl sulfoxide and filtered through a $0.2-\mu \mathrm{m}$ syringe filter.

\section{Cells}

RAW 264.7 cells, a murine macrophage cell line, were purchased from American Type Culture Collection and maintained in DMEM supplemented with $5 \mathrm{mg} / \mathrm{mL}$ glucose, $10 \%$ FBS, $1 \%$ penicillin-streptomycin at $37^{\circ} \mathrm{C}$ with $5 \%$ $\mathrm{CO}_{2}$. PBMCs were isolated as described by Panda et al. [8]. Five week-old ICR mice were purchased from Orient Bio (Suwon, Korea) and raised following guidelines from the Ethics Committee of Dankook University (DKU15-026). Mice were euthanized using $\mathrm{CO}_{2}$ and rinsed liberally with $70 \%$ ethanol. The mouse femurs and tibiae were removed and carefully cleaned of soft tissues. 

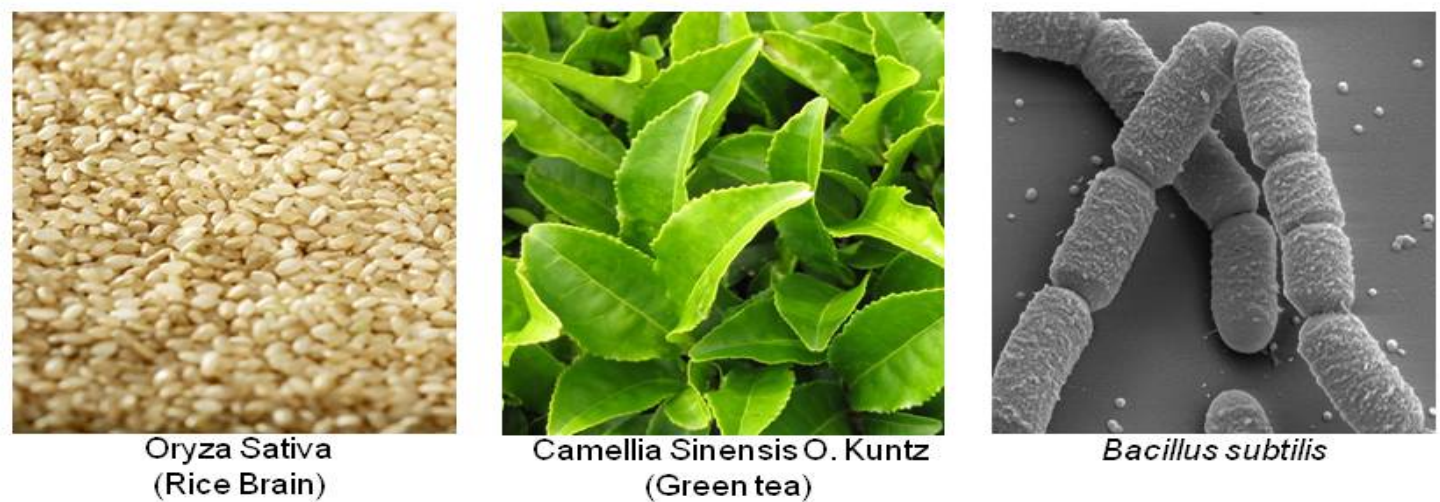

(Green tea)

Figure 1: Photograph of Oryza sativa, Camellia sinensis O. Kuntz, and Bacillus subtilis

The marrow was harvested by inserting a 20gauge syringe needle and flushing with minimum essential medium-alpha containing $20 \%$ FBS. Cells were inoculated and incubated in a $25 \mathrm{~cm}^{2}$ flask for $72 \mathrm{~h}$ at $37^{\circ} \mathrm{C}$ with $5 \%$ humidified $\mathrm{CO}_{2}$. Non-adherent PBMCs were removed and loaded for cell viability assessment under OCB.

\section{Cell viability assay}

The cytotoxic effect of OCB on RAW 264.7 cells and PBMCs was evaluated by the MTT assay. Briefly, cells were seeded at a density of $5 \times 10^{3}$ cells/well in a 96 -well plate for $24 \mathrm{~h}$. Cells were then treated with various concentrations of OCB with or without $1 \mu \mathrm{g} / \mathrm{mL}$ LPS. After $24 \mathrm{~h}, 5 \mathrm{mg} / \mathrm{mL}$ MTT was added to each well, and cells were incubated until formazan was constituted. The formazan was dissolved in MTT Iysis solution (20 $\%$ SDS, $50 \%$ dimethylformamide), and absorbance at $450 \mathrm{~nm}$ was measured using a microplate reader (Molecular Devices, Sunnyvale, CA, USA). Cell viability was calculated as cell viability in the OCB treated group versus that in the untreated control group. Each experiment was repeated three times.

\section{DPPH assay}

DPPH solution with methanol at $0.1 \mathrm{mM}$ was added to various concentrations of $\mathrm{OCB}$, using ascorbic acid as a positive control. After incubating for 30 min in dark, the absorbance of the samples was measured at $517 \mathrm{~nm}$ using a microplate reader. All data were converted to scavenging radical activity (S) using Eq 1.

$S(\%)=\{(A b-A s / A b)\} 100$

where $A b$ is the absorbance of blank and As is the absorbance of ascorbic acid- or OCB-treated samples. Each experiment was carried out in triplicate.

\section{Analysis of ROS}

Cells were pre-incubated for $1 \mathrm{~h}$ in presence or absence of $1 \mu \mathrm{g} / \mathrm{mL}$ LPS before the addition of OCB followed by addition of $10 \mu \mathrm{g} / \mathrm{mL}$, DCFHDA. After a 20-min incubation, the suspensions were washed with PBS and assayed with a flow cytometer (FACsort systems, Becton-Dickinson, Bedford, MA, USA).

\section{Glutathione (GSH) assay}

Cells were treated same as well as ROS anaylsis, and followed by measurement of total GSH and glutathione disulfide (GSSG) using a GSH/GSSG ratio detection assay kit. The assay was performed according to the manufacturer's instructions and repeated three times.

\section{Nitrite assay}

The production of NO by LPS-activated macrophages was measured with the Griess reagent system. Briefly, RAW 264.7 cells $\left(1 \times 10^{4}\right.$ cells/well $)$ were seeded onto 96-well plates and incubated for $24 \mathrm{~h}$. The cells were then treated with various concentrations of OCB with or without $1 \mu \mathrm{g} / \mathrm{mL}$ LPS for $24 \mathrm{~h}$, and the supernatant was removed. Fifty microliters of supernatant from OCB-treated wells was mixed with the same volume of Griess reagent $(1 \%$ sulfanilamide and 0.1 \% naphthylethylenediamine solution), and then incubated for $10 \mathrm{~min}$ at room temperature. Absorbance at $550 \mathrm{~nm}$ was read using a spectrophotometer (TECAN, Männedorf, Switzerland). The NO level was estimated as the percentage of absorbance of the sample relative to that of control.

\section{Real-time PCR}

RAW 264.7 cells $\left(1 \times 10^{6}\right.$ cells/well $)$ were plated in 6-well plates and incubated for $24 \mathrm{~h}$. Cells 
were then treated with various concentrations of OCB with or without $1 \mu \mathrm{g} / \mathrm{mL}$ LPS for $24 \mathrm{~h}$. After washing twice with PBS, total RNA was extracted using the TRIzol reagent (Life Technologies, Carlsbad, CA, USA) according to the manufacturer's instructions. The PCR template was prepared using the Quantitect SYBR green PCR kit (Qiagen, Venlo, The Netherlands) according to the manufacturer's instructions and quantitative PCR was performed using the Applied Biosystems 7500 (Life Technologies). Primer sequences are shown in Table 1. Quantitative analysis compared the $\Delta$ CT ratio of primers versus that of glyceraldehyde 3phosphate dehydrogenase (GAPDH) as an internal control.

Table 1: Primer sequences

\begin{tabular}{ll}
\hline Primer & Sequence \\
\hline $\begin{array}{l}\text { Inducible nitric } \\
\text { oxide species } \\
\text { (iNOS) }\end{array}$ & AGTGGTGTTCTTTGCTTC \\
Tumor necrosis & GCTTGCCTTATACTGGTC \\
factor alpha & ACGGCATGGATCTCAAAGAC \\
(TNF-a) & AGATAGCAAATCGGCTGACG \\
Cyclooxygenase & GGTCTGGTGCCTGGTCTG \\
type-2 (COX2) & CTCTCCTATGAGTATGAGTCT \\
Interleukin-6 (IL- & CTTCCATCCAGTTGCCTTCTT \\
6) & ACGATTTCCCAGAGAACATGT \\
\hline
\end{tabular}

\section{Prostaglandin $E_{2}$ assay}

Using supernatant collected from the NO assay, $\mathrm{PGE}_{2}$ concentrations with or without $\mathrm{OCB}$ in LPS-induced RAW 264.7 cells were measured using a specific enzyme immunoassay kit according to the manufacturer's instructions.

\section{High performance liquid chromatography (HPLC)}

OCB components were analyzed using Agilent 1260 model with a pump (G1311C), auto sampler (G1329B), column (G1316A), and UV detector (G1314F) purchased from Agilent (Santa Clara, CA, USA). We determined the HPLC conditions and separated the active ingredients of rice bran and green tea with reference to previous studies $[9,10]$. The analysis conditions are described in Table 2.

\section{Statistical analysis}

The results are presented as mean \pm standard deviation from three or more independent experiments. Data was compared using the Student's $t$-test and significant $p$-value was $^{\star} p<$ $0.1,{ }^{* *} p<0.05$, and ${ }^{* * *} p<0.001$. Prism ${ }^{\circledR}$ program VER 5.03 (GraphPad, La Jolla, CA, USA) was used for statistical analysis of the data.

\section{RESULTS}

\section{Cytotoxicity effect of OCB on macrophages}

The viability of RAW 264.7 macrophages under various concentrations of OCB was similar in the presence and absence of LPS (Figure 2). We also observed no cytotoxic effects of OCB on mouse PBMCs in the presence or absence of LPS.

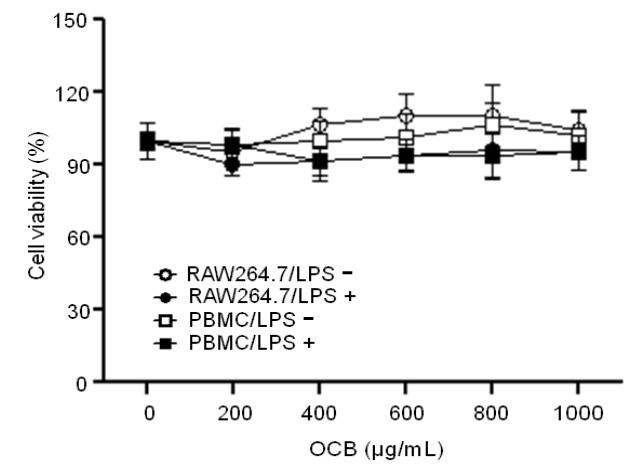

Figure 2: Cytotoxicity of OCB on LPS induced RAW 264.7 macrophages

Table 2: HPLC analysis conditions

\begin{tabular}{ll}
\hline Detector & UV detector \\
Wavelength. & $310 \mathrm{~nm}$ \\
Column & Aminex® HPX-87H lon Exclusion column $(300 \times 7.8 \mathrm{~mm}, 9 \mu \mathrm{m})$ \\
Mobile phase & $10 \mathrm{mM} \mathrm{H}_{2} \mathrm{SO}_{4}$ in water (isocratic) \\
Running time & $30 \mathrm{~min}$ \\
Flow rate & $0.5 \mathrm{~mL} / \mathrm{min}$ \\
Injection volume & $10 \mu \mathrm{l}$ \\
Temperature & $40{ }^{\circ} \mathrm{C}$ \\
\hline
\end{tabular}




\section{Anti-oxidant potency of OCB}

DPPH assay, commonly used in natural product anti-oxidant studies, is based on the idea that hydrogen donors are antioxidants and is used to assess the free radical scavenging ability of compounds.

We used ascorbic acid, a known free radical scavenger, as a positive control. We found that OCB demonstrated anti-oxidant activity in a dose-dependent manner (Figure 3A). Furthermore, we found that $500 \mu \mathrm{g} / \mathrm{mL}$ OCB had greater radical scavenger potency than $1 \mathrm{mg}$ of ascorbic acid $(p=0.0045)$.

\section{Effect of OCB on ROS production in LPS- induced macrophages}

LPS treatment increases cellular oxygen uptake and induces the release of intracellular ROS. To determine whether OCB can alter LPS-induced intracellular redox states, we examined ROS production levels. LPS treatment alone significantly increased ROS levels from $66.6 \%$ to $72.9 \%$ in RAW 264.7 macrophages (Figure 3 B). However, OCB reduced LPS-induced ROS production in a dose-dependent manner from $68.9 \%$ to $56.6 \%$.
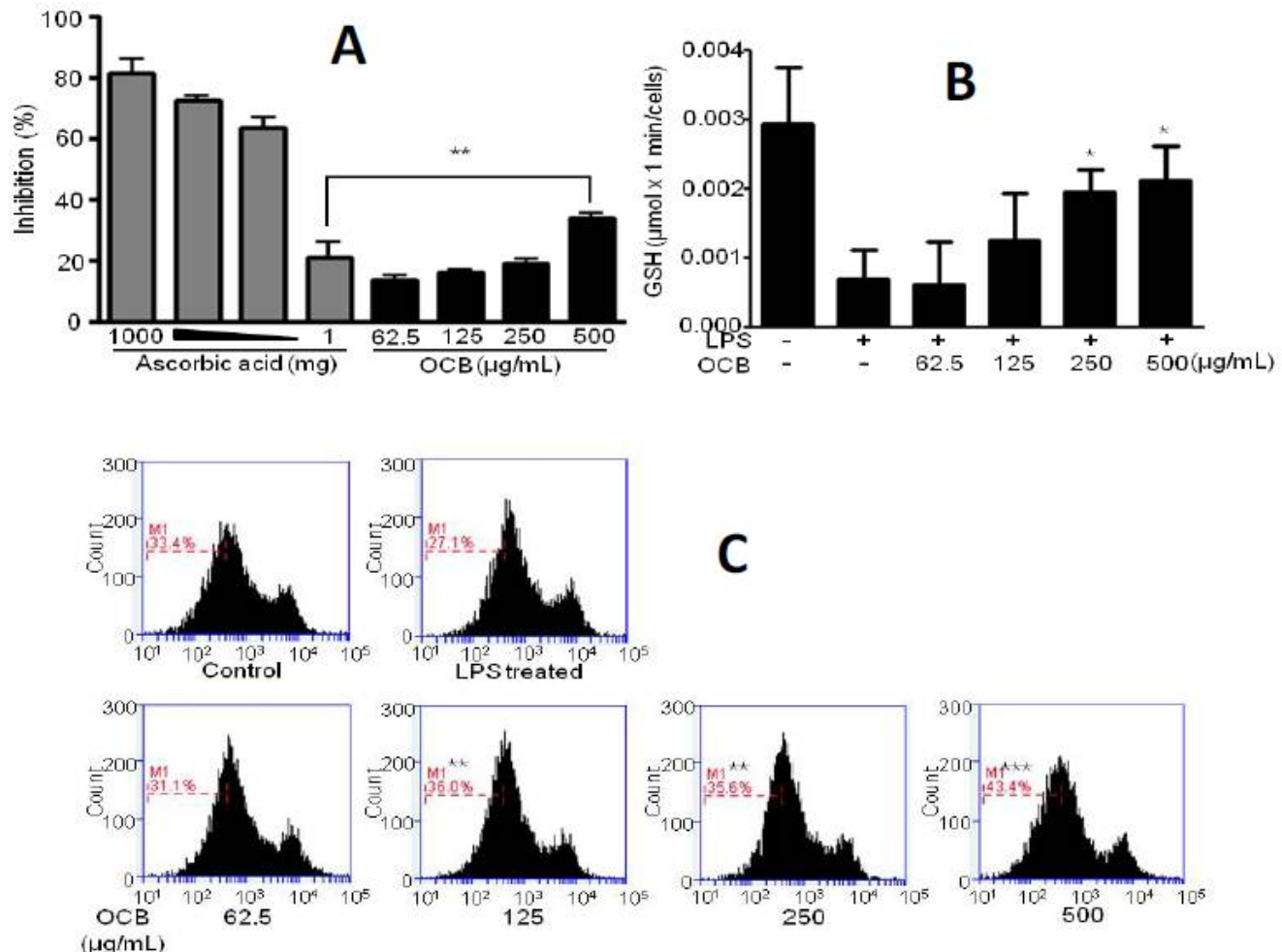

Figure 3: Anti-oxidant effect of OCB on LPS-induced macrophages. (A) DPPH assay, all data was converted into percentage of scavenging radical by the following Eq 2. ; LPS treatment alone significantly increased ROS levels from $66.6 \%$ to $72.9 \%$ in RAW 264.7 macrophages (C). However, OCB reduced LPS-induced ROS production in a dose-dependent manner from $68.9 \%$ to $56.6 \%$ analysis by flow cytometer. (B) GSH assay. Data was compared using the student's $t$-test and significant $p$-value was ${ }^{*} p<0.1$, ${ }^{* *} p<0.05$, and ${ }^{* * *} p<0.001$ 
(A)

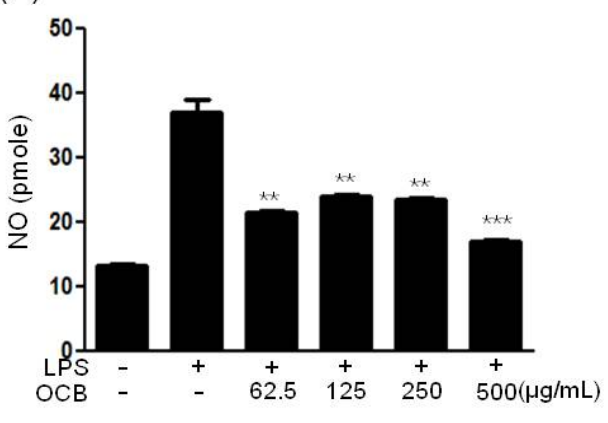

(C)

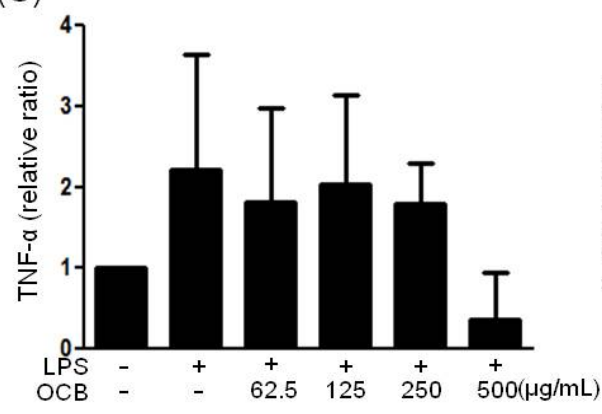

(B)

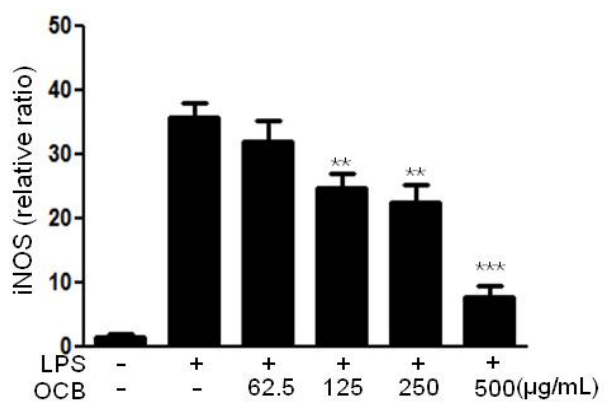

(D)

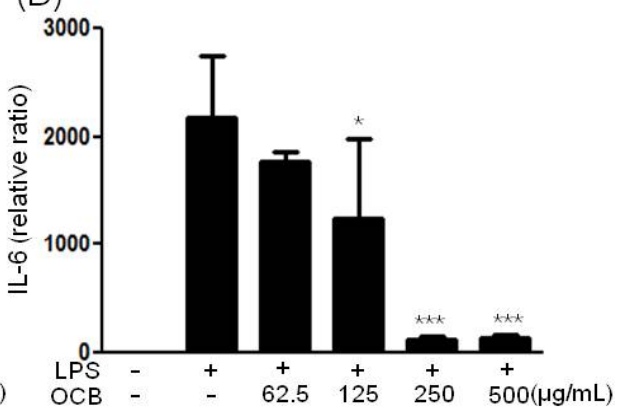

(E)

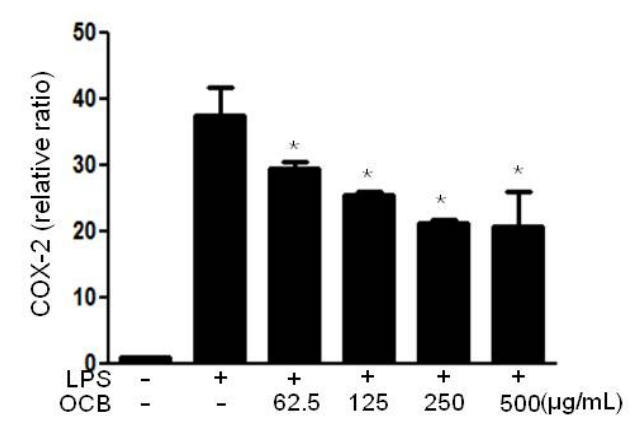

$(\mathrm{F})$

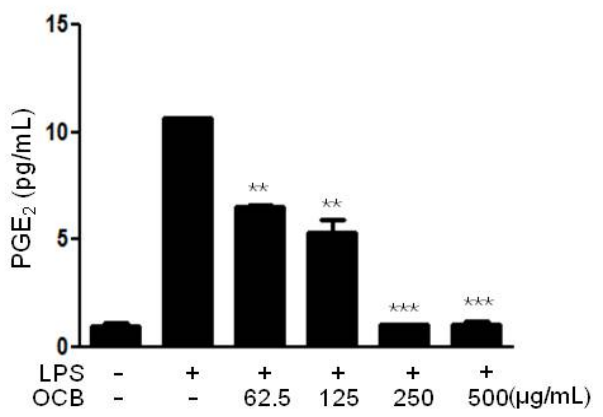

Figure 4: Effects of OCB on levels of (A) NO, (B) iNOS, (C) TNF-a, (D) IL-6, (E) COX-2, and (F) PGE 2 in LPSinduced macrophages. Data were compared using Student's $t$-tests, and significance is indicated as ${ }^{*} p<0.1,{ }^{* *} p$ $<0.05,{ }^{* * *} p<0.001$

\section{Effect of OCB on pro-inflammation cytokines in LPS-induced macrophages}

To determine the effect of OCB on proinflammatory cytokine expression in LPS-induced RAW 264.7 macrophages, mRNA and protein levels of iNOS, TNF- $\alpha$, IL-6, COX-2, and PGE ${ }_{2}$ were measured by quantitative PCR and ELISA, respectively. OCB treatment reduced the transcriptional levels of iNOS (Figure 4B), IL-6 (Figure $4 \mathrm{D}$ ), and COX-2 (Figure $4 \mathrm{E}$ ) and the protein level of $\mathrm{PGE}_{2}$ (Figure $4 \mathrm{~F}$ ). OCB treatment also reduced the transcriptional level of TNF- $\alpha$, but this was not statistically significant (Figure $4 \mathrm{C}$ ).

\section{OCB constituents}

Using HPLC, we isolated 9 leading compounds from the OCB product. The HPLC conditions are described in Table 2. As shown in Figure 4, the compounds isolated with their separation time in parentheses were ECG (8.985 min), cathechin (11.861 min), suringin acid (17.507 $\mathrm{min})$, epicathechin (18.260 min), EGCG (18.602 min), rutin $(24.705 \mathrm{~min})$, isoquercetin $(25.605 \mathrm{~min}$ ), tolirin (67.848 $\mathrm{min}$ ), and linoleic acid (87.911 min). The contents are described in Table 3.

\section{DISCUSSION}

Although enzyme bath reportedly increases activity of the immune system and have been used as a folk remedy for various skin disease including atopic dermatitis, acne, psoriasis, and blood circulation, there has been little scientific inquiry into the mechanisms underlying their physiological benefits. We hypothesized that 


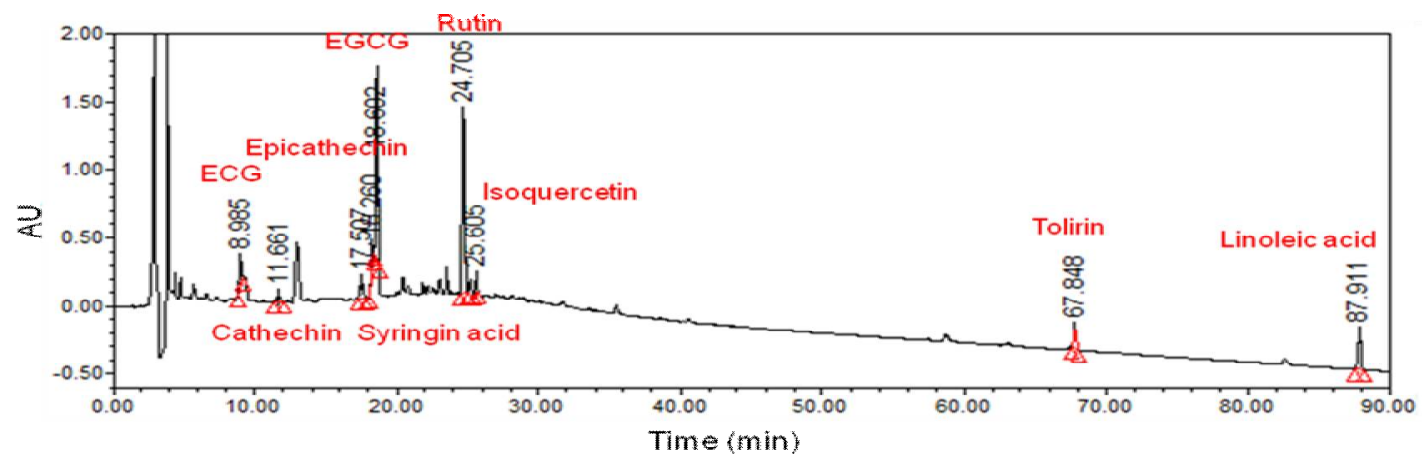

Figure 5: HPLC chromatogram of OCB components using an Agilent 1260 system and the analysis conditions described in Table 2

enzyme bath inhibits production of free radicals and regulates the activation of pro-inflammatory factors in tissues.

Table 3: Major compounds of OCB based on HPLC analysis

\begin{tabular}{lc}
\hline Major compound & Content $(\mathbf{m g} / \mathbf{g})$ \\
\hline ECG & 0.397 \\
Cathechin & 0.439 \\
Syringin acid & 1.663 \\
Epicathechin & 1.088 \\
EGCG & 8.516 \\
Rutin & 1.699 \\
Isoquerctin & 1.218 \\
Tolorin & 5.331 \\
Linoleic acid & 18.221 \\
\hline
\end{tabular}

To determine whether the ethanol extraction of OCB is cytotoxic, we performed cell viability analysis using cultured primary PBMCs and RAW 264.7 macrophages. We found that OCB extract had no cytotoxic effects on PBMCs or RAW 264.7 macrophages regardless of the presence of LPS. As oxidative stress related to ROS can induce inflammation and degrade intracellular proteins, lipids, and nucleic acids [11], we assessed the ability of OCB to reduce oxidative stress in target cells using DPPH assay, flow cytometry, and GSH assay. In the DPPH assay, OCB showed a potency as a free radical scavenger as well as ascorbic acid. OCB also attenuated LPS-stimulated ROS production.

Glutathione in its reduced from is a tripeptide composed of L-cysteine, L-glutamic acid and glycine. It is the smallest intracellular thiolcontaining protein in all cells and prevents cell damage caused by ROS such as free radicals and peroxides. We found that LPS reduced GSH activity, whereas OCB treatment reversed this effect in a dose-dependent manner. Thus, OCB appears to attenuate the intracellular depletion of GSH in its reduced form.

ROS and pro-inflammatory cytokines act synergistically through an ROS/RNS-cytokine- transcription factor regulatory loop, thereby augmenting the inflammatory response and exacerbating tissue damage $[11,12]$. Excessive production of $\mathrm{NO}$ and prostaglandins induced by iNOS is considered to be the most prominent molecular mechanism in the inflammatory process [13]. We observed that the production of NO and iNOS in LPS-induced murine macrophages was reduced by OCB treatment.

During inflammation, macrophages have three major functions: antigen presentation [14], phagocytosis [15], and immunomodulation $[15,16]$, which is mediated through the production of various cytokines and growth factors. The inflammatory process is usually tightly regulated, involving both signals that initiate and maintain inflammation and signals that resolve inflammation. An imbalance between these two types of signals leaves inflammation unchecked, resulting in cellular and tissue damage. We found that OCB dose-dependently inhibited the expression of TNF- $\alpha, \mathrm{IL}-6, \mathrm{COX}-2$, and PGE 2 . Furthermore we identified, key components in the OCB extract using HPLC.

Compared to the yields of active ingredients in OCB extract in other reports, we demonstrated that products from OCB fermentation could be extracted on the order of milligrams rather than micrograms. Ahmad et al. reported that ethanol was most efficient for ECG or EGCG extraction from green tea. According to their HPLC analysis, ECG yield was $0.17 \pm 0.002 \mathrm{mg} / \mathrm{g}$ and EGCG yield was $1.635 \pm 0.18 \mathrm{mg} / \mathrm{g}$ on average [17].

We also found significant amounts of linolenic acid $(18.221 \mathrm{mg} / \mathrm{g})$, ECG $(0.397 \mathrm{mg} / \mathrm{g})$, EGCG $(8.516 \mathrm{mg} / \mathrm{g})$, and tolorin $(5.331 \mathrm{mg} / \mathrm{g})$ in the OCB extract. These compounds are well-known anti-oxidants [9, 18], and the extraction efficiency in our experiments was more than double that of previous experiments. This increased extraction efficiency likely results from the fermentation process using microorganisms. Ultimately, these results demonstrate that the reduction of 
inflammatory cytokines by OCB plays a crucial role in regulating inflammation through ROS suppression (Figure 6) and that using fermentation could allow higher extraction efficiency.

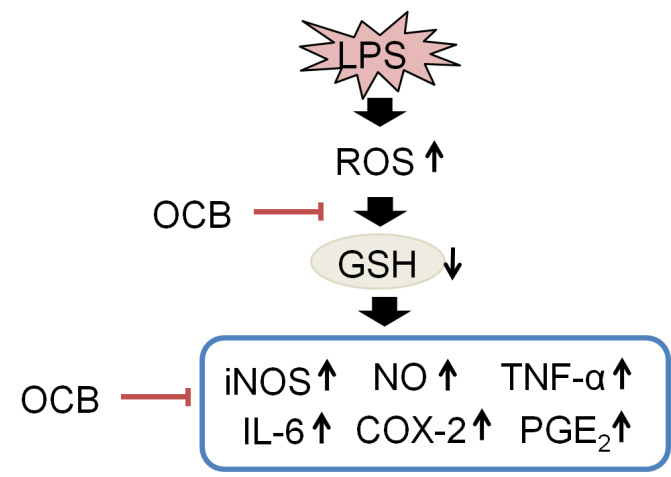

Figure 6: A schematic illustration of antioxidant and anti-inflammation activities of rice bran and green tea fermentation

\section{CONCLUSION}

The findings of this work suggest that the fermentation of rice bran and green tea using $B$. subtilis is capable of poducing high yields of compounds and can critically modulate proinflammatory factors via $\mathrm{GSH}$ and ROS regulation. Thus, the product of OCB fermentation may be used as a synergistic adjuvant therapy for inflammatory diseases by acting as a radical scavenger and ROS inhibitor.

\section{DECLARATIONS}

\section{Acknowledgement}

This research was supported by Basic Science Research Program through the National Research Foundation of Korea (NRF) funded by Republic of Korea Ministry of Education (no. 2017R1D1A1B03030060), a grant of the Korea Health Technology R\&D Project through the Korea Health Industry Development Institute (KHIDI), funded by Ministry of Health \& Welfare, Republic of Korea (grant no. HI15C1524), and Research Fund of Dankook University in 2016.

\section{Conflict of interest}

The authors declare that they have no competing interests with regard to this work.

\section{Contribution of authors}

We declare that this work was done by the authors named in this article and all liabilities pertaining to claims relating to the content of this article will be borne by the authors.

\section{REFERENCES}

1. Roschek B, Jr., Fink RC, Li D, McMichael M, Tower CM, Smith $R D$, Alberte RS. Pro-inflammatory enzymes, cyclooxygenase 1, cyclooxygenase 2, and 5lipooxygenase, inhibited by stabilized rice bran extracts. J Med Food 2009; 12: 615-623.

2. Justo ML, Claro C, Zeyda M, Stulnig TM, Herrera MD, Rodriguez-Rodriguez $R$. Rice bran prevents high-fat diet-induced inflammation and macrophage content in adipose tissue. Eur J Nutr 2016; 55: 2011-2019.

3. Choi SP, Kim SP, Kang MY, Nam SH, Friedman M. Protective effects of black rice bran against chemicallyinduced inflammation of mouse skin. J Agric Food Chem 2010; 58: 10007-10015.

4. Nicod N, Chiva-Blanch G, Giordano E, Davalos A, Parker RS, Visioli F. Green tea, cocoa, and red wine polyphenols moderately modulate intestinal inflammation and do not increase high-density lipoprotein (HDL) production. J Agric Food Chem 2014; 62: 2228-2232.

5. Sartor L, Pezzato E, Dona M, Dell'Aica I, Calabrese F, Morini M, Albini A, Garbisa S. Prostate carcinoma and green tea: (-)epigallocatechin-3-gallate inhibits inflammation-triggered MMP-2 activation and invasion in murine TRAMP model. Int J Cancer 2004; 112: 823-829.

6. Shen CL, Yeh JK, Samathanam C, Cao JJ, Stoecker BJ, Dagda RY, Chyu MC, Dunn DM, Wang JS. Green tea polyphenols attenuate deterioration of bone microarchitecture in female rats with systemic chronic inflammation. Osteoporos Int 2011; 22: 327-337.

7. Wen WC, Kuo PJ, Chiang CY, Chin YT, Fu MM, Fu E. Epigallocatechin-3-gallate attenuates Porphyromonas gingivalis lipopolysaccharide-enhanced matrix metalloproteinase-1 production through inhibition of interleukin-6 in gingival fibroblasts. J Periodontol 2014; 85: $868-875$.

8. Panda SK, Kumar S, Tupperwar NC, Vaidya T, George A, Rath S, Bal V, Ravindran B. Chitohexaose activates macrophages by alternate pathway through TLR4 and blocks endotoxemia. PLoS Pathog 2012; 8: e1002717.

9. Jun HI, Song GS, Yang El, Youn Y, Kim YS. Antioxidant activities and phenolic compounds of pigmented rice bran extracts. J Food Sci 2012; 77: C759-764.

10. Zigoneanu IG, Williams L, Xu Z, Sabliov CM. Determination of antioxidant components in rice bran oil extracted by microwave-assisted method. Bioresour Technol 2008; 99: 4910-4918.

11. Kim YO, Lee $S W$, Oh $\mathrm{CH}$, Rhee $\mathrm{YH}$. Hericium erinaceus suppresses LPS-induced pro-inflammation gene activation in RAW264.7 macrophages. Immunopharmacol Immunotoxicol 2012; 34: 504-512.

12. Zolali E, Asgharian P, Hamishehkar H, Kouhsoltani M, Khodaii $H$, Hamishehkar $H$. Effects of gamma oryzanol on factors of oxidative stress and sepsis-induced lung 
injury in experimental animal model. Iran J Basic Med Sci 2015; 18: 1257-1263.

13. Lin CY, Lee CH, Chang YW, Wang HM, Chen CY, Chen $Y H$. Pheophytin a inhibits inflammation via suppression of LPS-induced nitric oxide synthase-2, prostaglandin E2, and interleukin-1beta of macrophages. Int J Mol Sci 2014; 15: 22819-22834.

14. Fujiwara K, Kitatani K, Fukushima K, Yazama $H$, Umehara $H$, Kikuchi M, Igarashi $Y$, Kitano H, Okazaki $T$. Inhibitory effects of dietary glucosylceramides on squamous cell carcinoma of the head and neck in NOD/SCID mice. Int J Clin Oncol 2011; 16: 133-140.

15. Seong KJ, Lee HG, Kook MS, Ko HM, Jung JY, Kim WJ. Epigallocatechin-3-gallate rescues LPS-impaired adult hippocampal neurogenesis through suppressing the
TLR4-NF-kappaB signaling pathway in mice. Korean $J$ Physiol Pharmacol 2016; 20: 41-51.

16. Loft S, Deng XS, Tuo J, Wellejus A, Sorensen $M$, Poulsen HE. Experimental study of oxidative DNA damage. Free Radic Res 1998; 29: 525-539.

17. Ahmad RS, Butt MS, Huma N, Sultan ST, Arshad MU, Mushtaq Z, Saeed F. Quantitative and qualitative portrait of green tea catechins (GTC) through HPLC. International Journal of Food Properties 2014; 17: 16261636.

18. Chiou $T Y$, Kobayashi T, Adachi S. Characteristics and antioxidative activity of the acetone-soluble and insoluble fractions of a defatted rice bran extract obtained by using an aqueous organic solvent under subcritical conditions. Biosci Biotechnol Biochem 2013; 77: $624-630$ 